\title{
Voluntary medical male circumcision and sexual practices among sexually active circumcised men in Mzuzu, Malawi: a cross- sectional study
}

Zimveka Jones Chatsika ${ }^{1,2^{*}}$, Andrew Kumitawa', Vincent Samuel ${ }^{3}$, Steven Chifundo Azizi ${ }^{4,5}$ and Vincent C. Jumbe ${ }^{6}$

\begin{abstract}
Background: Voluntary Medical Male Circumcision (VMMC) is one of the strategies being promoted to prevent sexual heterosexual transmission of HIV. It has been adopted by 14 countries with high HIV prevalence and low circumcision rates. The $60.0 \%$ protective efficacy of VMMC has come with misconceptions in some societies in Malawi, hence VMMC clients may opt for risky sexual practices owing to its perceived protective effect. The study estimated proportion of circumcised men engaging in risky sexual behaviors post-VMMC, assessed knowledge on VMMC protective effect and identified socio-demographic factors associated with risky sexual practices.

Method: A cross sectional study was conducted at two sites of Mzuzu city. Systematic random sampling was used to select 322 participants aged 18-49 who had undergone VMMC. The independent variables included age, location, occupation, religion, marital status and education. Outcome variables were non condom use, having multiple sexual partners and engaging in transactional sex. Data from questionnaires was analyzed using Pearson's chi square test and logistic regression.

Results: Out of 322 respondents, 84.8\% (273) understood the partial protection offered by VMMC in HIV prevention. Ninety-six percent of the participants self-reported continued use of condoms post VMMC. Overall 23.7-38.3\% participants self-reported engaging in risky sexual practices post VMMC, $23.7 \%$ (76) had more than one sexual partner; $29.2 \%$ (94) paid for sex while 39.9\% $(n=187)$ did not use a condom. Residing in high density areas was associated with non-condom use, $(p=0.043)$. Being single $(p<0.001)$, and residing in low density areas $(p=0.004)$ was associated with engaging in transactional sex.

Conclusion: Risky sexual practices are evident among participants that have undergone VMMC. Messages on safer sexual practices and limitations of VMMC need to be emphasized to clients, especially unmarried or single and those residing in low density areas.
\end{abstract}

Keywords: Voluntary medical male circumcision, Risky practice, HIV, Condom, Transactional sex, Malawi

* Correspondence: czimvekajones@gmail.com

${ }^{1}$ College of Medicine, Public Health Department, P/Bag 360, Chichiri, Blantyre

3, Malawi

${ }^{2}$ Malawi Defence Force, Malawi Military Health Services, Moyale Barracks, P.O

Box 23, Mzuzu, Malawi

Full list of author information is available at the end of the article

(c) The Author(s). 2020 Open Access This article is distributed under the terms of the Creative Commons Attribution 4.0 International License (http://creativecommons.org/licenses/by/4.0/), which permits unrestricted use, distribution, and reproduction in any medium, provided you give appropriate credit to the original author(s) and the source, provide a link to the Creative Commons license, and indicate if changes were made. The Creative Commons Public Domain Dedication waiver (http://creativecommons.org/publicdomain/zero/1.0/) applies to the data made available in this article, unless otherwise stated. 


\section{Background}

HIV and AIDS pose a major threat to health and livelihood world-wide. Of the 37 million people living with HIV worldwide, $70.0 \%$ of these live in sub-Saharan Africa and Malawi accounts for 4.0\% [1-3]. Malawi has an HIV prevalence of $8.8 \%$ among men and women aged 15-49 [2]. Approximately 5600 people worldwide contract HIV daily $[1,4]$ and 790,000 adults and children died of AIDS related illnesses, accounting for $66.0 \%$ of AIDS related deaths worldwide [1, 4]. An estimated 1 million people in the Sub Saharan region contract HIV annually as of 2017 $[1,4,5]$. In 2017, Malawi registered 39,000 new HIV infections and 17,000 deaths due to AIDS related illnesses in all ages $[1,4]$. Heterosexual contact is the major mode of HIV transmission and accounts for $88.0 \%$ of the infections [2]. Access to prevention and treatment from this incurable disease is limited in sub-Saharan Africa and the disease affects mostly the productive age group [6]. In this regard, efforts tailored at reducing HIV transmission and averting deaths is a welcome development. However, there are several types of prevention strategies to reduce the risk of acquiring or transmitting HIV such as behavioral, biomedical and structural that are complementary $[7,8]$.

Voluntary medical male circumcision (VMMC) is a biological intervention and an effective strategy in reducing sexual transmission of HIV from women to men [9-11]. In 2007, the Joint United Nations Programme on HIV/ AIDS (UNAIDS) and the World Health Organization (WHO) recommended scale up of Male Circumcision (MC) and has been adopted as one of the HIV preventive strategies in countries with low levels of MC [12]. Globally, the estimated prevalence rate of male circumcision is around $38.7 \%$ with half of the circumcisions conducted for religious and cultural reasons [13, 14]. Only $28.0 \%$ of the men aged 15-49 in Malawi are circumcised [3]. This figure includes $18.0 \%$ circumcised by traditional practitioners and $9.0 \%$ by medical professionals [3]. Hence the percentage for those that undergo VMMC is significantly low. Male circumcision is effective when done between the ages of 15 to 20 years and its effect declines with increase in age as the risk of contracting HIV decreases [15].

Evidence of male circumcision on HIV prevention came from meta-analysis of three randomized controlled trials involving 11,050 men that were conducted in South Africa, Kenya, and Uganda which showed a relative risk reduction for contracting HIV infection in circumcised men to be around 60.0\% (95\% CI 40.0-67.0\%) [16, 17]. Consequently, recommendations were made by $\mathrm{WHO}$ and UNAIDS to countries with low rates of male circumcision and high HIV prevalence rate to adopt VMMC as a measure to prevent HIV transmission alongside other preventive strategies such as condom use. Following this development, Malawi as one of 14 prioritized countries according to $\mathrm{WHO}$ and UNAIDS, adopted and rolled out VMMC in 2011 as one of its HIV preventive strategies [18, 19]. A total of 266,176 VMMCs have so far been performed as of 2015 representing $13.0 \%$ of the target that was set in 2011 [20]. Circumcising more than $80.0 \%$ of males aged 15 to 49 in a high HIV prevalent region could avoid 3.36 million infections and 386,000 deaths by 2025 [21].

VMMC clients undergo counselling and HIV testing prior to the circumcision procedure where they are informed about the advantages of VMMC and the need to use other HIV prevention strategies including being faithful to one partner, abstaining from sex for a period of 6 weeks following VMMC, and also consistent and correct condom use [22, 23]. During counselling, the protective effect of VMMC which is at $60.0 \%$ (as a scientific explanation) is interpreted as a lowered risk of contracting HIV if circumcised [22, 23]. This explanation creates and leaves room for misconceptions and poses a considerable threat to the main preventive effort [23]. It was also noted that the media utilizes this ' $60.0 \%$ ' protection in promoting VMMC messages against HIV infection, which was observed in a trial by Auvert et al. [9].

A study conducted in Kenya involving 1344 men showed that $30.7 \%$ were involved in early resumption of sex [24]. This is one of the risky sexual practices following VMMC, which may be as a result of the misunderstanding of the protective effect of VMMC [24]. Furthermore, the desire to be circumcised was associated with knowledge of the perceived protective effect of VMMC among the uncircumcised individuals who were practicing risky sexual behaviours as well as high incidence of STIs in circumcised clients $[21,25]$. In this case, the motivation to get circumcised could be associated with the desire to freely engage in risky sexual practices due to the perceived protective effect of VMMC. This may point to the lack of understanding as regards the protective effect of VMMC, a development which may contribute to further risky sexual practice among circumcised men hence putting them at risk of contracting HIV.

It is worth noting that womens' desire for circumcised men, enhanced sexual pleasure, religion, proven safety, affordability, confidentiality and being hygienic prompted participants to go for circumcision [19, 26]. In Malawi, the desire to have more women was the motivating factor for the adolescent boys to get circumcised [21]. There are limited studies on risky sexual practices associated with "60.0\% protective effect" of VMMC in Malawi [27]. This study was conducted to determine if circumcised men were likely to engage in risky sexual practices in Mzuzu City owing to the perceived protective effect that VMMC offers.

\section{Methods}

Study design and study setting

A cross section study was conducted in two health facilities of Mzuzu city located in the northern region of 
Malawi between 12 February, 2017 and 11 May, 2017. Mzuzu city was chosen since it has two public health facilities that provide free VMMC services to the community with support from partners Jhpiego Malawi and Project Concern International (PCI) Malawi.

\section{Study population}

All men aged 18 to 49 years who underwent voluntary medical male circumcision were eligible for the study.

\section{Inclusion criteria and exclusion criteria}

The study included men aged 18 to 49 years that had undergone VMMC at any of the two sites and 6 months had elapsed following procedure were eligible for the study. On the contrary, those who were very sick were not included in the study.

\section{Variables}

The explanatory variables included socio demographic characteristics; age, occupation, marital status, education, religion and place of residence. Outcome variables were risky sexual practices. Risky sexual practice constituted three indicators namely: transactional sex in all men who reported to have ever engaged in transactional sex, multiple sexual partners in those that had more than one sexual partner and non-condom use in those that did not use a condom during last sex to a nonmarital or cohabiting partner.

\section{Sampling and sample size determination}

The two government owned facilities that provide free VMMC services were both used to sample participants for the study. Sample size was determined using STATA version 12 with $31.0 \%$ proportion [24], level of statistical significance at 5.0, 95\% confidence interval and margin of error; 0.05 . The calculated overall sample size was 322 participants.

Systematic random sampling was used to select study participants. Those waiting to collect medication at the pharmacy following consultation were approached. Every 5th male client was selected until the sample size was reached.

\section{Data collection}

An interviewer administered structured questionnaire [28] was used to collect data. Data was collected by two Research Assistants (RAs) and the Principle Investigator (PI). Research assistants were trained in data collection methods and management for 3 days, followed by 1 day of fieldwork pre-testing. The questionnaire had three components: socio-demographic factors, sexual practice assessment and the interpretation of VMMC messaging to prevent HIV. The English questionnaire was translated into Chitumbuka and Chichewa languages. The translated questionnaires were then back-translated to English to maintain meaning and consistency. The tool was piloted with 10 participants and was amended to capture all the relevant information.

The PI and the RAs approached potential research participants and sought their informed consent prior to data collection. At the end of each day, the PI checked the questionnaires for completeness and consistency and provided feedback to data collectors where necessary. Data was double entered into a secure password protected Microsoft Excel (2007) database and cleaned before analysis. Statistical analysis was done using STATA version 12 (Stata corp., college station, Texas: Statacorp LP, USA).

\section{Data analysis}

Proportions and frequencies for categorical variables were calculated. Pearson's Chi-square test was used to analyze categorical data for associations and relationships between the variables. Odds ratio was used as a measure of effect. Logistic regression was also used to control for confounding. Statistical tests were assessed at significance level of 0.05 and confidence level of $95 \%$.

\section{Ethical approval and consent to participate}

Ethical approval was obtained from the College of Medicine Research Ethics Committee in Malawi (reference number P.10/16/2035). Written permission to conduct the study was obtained from Mzuzu and Moyale health facilities. Informed written consent were obtained from study participants. Willingness to participate in the study was confirmed by signing or thumb printing on the informed consent sheet.

\section{Results}

Socio-demographic characteristics of the study participants

Out of the 322 participants, 154 (47.8\%) were recruited from Mzuzu Health Centre and 168 (52.2\%) were from Moyale Health Facility. The participants' mean age was 27.6 years $\mathrm{SD} \pm 6.8$ (range: 18 to 48 ). Two-thirds of the sample comprised of men aged 18 to 29 , representing $66.8 \%$ of total sample; $51.2 \%$ of the participants were married, $66.8 \%$ came from high density locations, $72.4 \%$ attained secondary education, $83.6 \%$ were Christians and $34.8 \%$ were students (Table 1 ).

Proportion of participants engaging in risky sexual practices Sexual practices of study participants post VMMC showed that the proportion of participants that selfreported engaging in risky sexual practice post VMMC was $38.2 \%(n=322)$. About $23.7 \%(n=322)$ reported having multiple sexual partners; $29.2 \%(n=322)$ reported being involved in transactional sex while $36.9 \%(n=187)$ 
Table 1 Socio-demographic characteristics of participants ( $n=$ 322)

\begin{tabular}{|c|c|c|}
\hline Characteristic & $n$ & $\%$ \\
\hline \multicolumn{3}{|l|}{$\overline{\text { Age }}$} \\
\hline $18-24$ & 131 & 40.7 \\
\hline $25-29$ & 84 & 26.1 \\
\hline $30-34$ & 55 & 17.1 \\
\hline $35-39$ & 30 & 9.3 \\
\hline $40-49$ & 22 & 6.8 \\
\hline \multicolumn{3}{|l|}{ Marital status } \\
\hline Single & 153 & 47.5 \\
\hline Married & 165 & 51.2 \\
\hline Widowed & 1 & 0.3 \\
\hline Divorced/Separated & 3 & 0.9 \\
\hline \multicolumn{3}{|l|}{ Area of residence } \\
\hline Low density & 107 & 33.2 \\
\hline High density & 215 & 66.8 \\
\hline \multicolumn{3}{|l|}{ Education level } \\
\hline Primary & 48 & 14.9 \\
\hline Secondary & 233 & 72.6 \\
\hline Tertiary & 41 & 12.7 \\
\hline \multicolumn{3}{|l|}{ Religion } \\
\hline Christian & 269 & 83.5 \\
\hline Islam & 38 & 11.8 \\
\hline Other & 15 & 4.7 \\
\hline \multicolumn{3}{|l|}{ Employment status } \\
\hline Not employed & 35 & 10.9 \\
\hline Student & 112 & 34.8 \\
\hline Business & 90 & 28.0 \\
\hline Farmer & 26 & 8.1 \\
\hline Formal employment & 59 & 18.3 \\
\hline
\end{tabular}

reported non-condom use in the past 6 months. On the other hand, 32.3\% (104) had sex prior to the recommended 6 weeks abstinence period (VMMC healing period) (Table 2).

\section{Perceived protective effect of VMMC}

The results showed that $50.0 \%(n=322)$ of the participants self-reported undergoing VMMC for HIV prevention,

Table 2 Proportions of participants that engaged in risky sexual practice

\begin{tabular}{llll}
\hline Variable & Number & $\%$ & $95 \% \mathrm{Cl}$ \\
\hline No condom use & $69(n=187)$ & 36.9 & $29.91,43.87$ \\
Paid sex & $94(n=322)$ & 29.2 & $23.90,33.85$ \\
Multiple sex partners & $76(n=322)$ & 23.6 & $18.94,28.27$ \\
Overall proportion & $123(n=322)$ & 38.2 & $32.86,43.53$ \\
\hline
\end{tabular}

$30.4 \%$ for hygiene purposes and $19.6 \%$ for other reasons (tradition $2.2 \%$, religion $5.9 \%$, medical reasons $5.3 \%$, and peer pressure $6.2 \%)$. The results also show that $84.8 \%$ of the respondents reported understanding the partial protection offered by VMMC and that one can still acquire the virus even after circumcision. Only $12.7 \%$ of the participants reported that VMMC provides total protection to HIV infection and $2.5 \%$ were unsure. On the benefits offered by VMMC, 58.1\% stated VMMC helps in the prevention of HIV and STIs, while 37.3\% sited hygienic reasons and 4.7\% felt it was for sexual pleasure. When participants were asked about the fear of contracting HIV following VMMC, $45.7 \%$ of participants stated that they have no fear of contracting HIV following VMMC while $54.4 \%$ are still afraid of contracting HIV despite having undergone VMMC. On condom use post VMMC, $94.4 \%$ agreed to continued condom use following circumcision. In addition, participants understand that a circumcised man can contract HIV (96.5\%) and that an infected circumcised man can still transmit HIV (98.4\%) (Table 3).

Table 3 Perception of the protective effect offered by VMMC $(n=322)$

\begin{tabular}{lll}
\hline Reasons for undergoing VMMC & $\mathrm{n}$ & $\%$ \\
HIV prevention & 161 & 50.0 \\
Hygiene & 98 & 30.4 \\
Others & 73 & 19.6
\end{tabular}

Perceived understanding of VMMC protection against HIV transmission $(n=322)$

Item

Provides total protection

n $\quad \%$

Provides partial protection

$41 \quad 12.7$

Does not understand

Benefits of VMMC $(n=322)$

$273 \quad 84.8$

Prevention of HIV, STI \& cancer

$8 \quad 2.5$

Hygiene

n $\%$

Sexual pleasure

$187 \quad 58.1$

VMMC and fears of HIV $(n=322)$

$15 \quad 4.7$

Fear reduced

Fear not reduced

Condom use following VMMC

$175 \quad 54.4$

Continued use

n $\%$

No condom use

$304 \quad 94.4$

Transmission of HIV in the infected circumcised

$18 \quad 5.6$

Can still transmit HIV

n $\%$

Cannot transmit HIV

$317 \quad 98.5$

Contracting HIV following VMMC

$5 \quad 1.6$

Can contract HIV

n $\%$

$311 \quad 96.6$

Cannot contract HIV

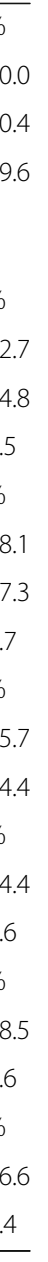




\section{Sexual practices}

On the type of sexual partner, it was observed that $43.5 \%$ had sex with a marital partner, $29.2 \%$ paid for sex while $27.3 \%$ had a non-cohabiting partner. Results of the participants' sexual practices post VMMC showed that $76.4 \%(n=322)$ of the participants reported having only one sexual partner. Aside those that did not use a condom because they are married, $22.0 \%(n=70)$ of the participants did not use a condom during their last sexual encounter with a non-cohabiting partner. Several reasons were cited for the non-condom use (condoms not available $6.2 \%$, feeling safe due to VMMC 7.1 and $8.7 \%$ forgot to use a condom). Of those that had a risky sexual act despite being single or married, $36.9 \%(n=187)$ did not use a condom. In addition, $32.3 \%$ were involved in sex prior to the recommended 6 weeks abstinence period post VMMC while $11.8 \%$ had a sexually transmitted infection (Table 4).

\section{Socio-demographic factors associated with risky sexual practices}

As explained in the data analysis section, non-condom use, multiple sexual partners and being involved in transactional sex are the proxy indicators for risky sexual practices. While several demographic factors were tested for association with the risky sexual practices, the results

Table 4 Characteristics of sexual practices among circumcised participants

\begin{tabular}{lll}
\hline Number of sexual partners $(n=322)$ & $\mathrm{n}$ & $\%$ \\
One partner & 246 & 76.4 \\
More than one partner & 76 & 23.6 \\
Condom ( $n=322)$ use last encounter & $\mathrm{n}$ & $\%$ \\
Used condom & 118 & 36.7 \\
Did not use condom & 204 & 63.4 \\
Reason condom not used $(n=204)$ & $\mathrm{n}$ & $\%$ \\
Marital partner & 134 & 65.7 \\
Condoms not available & 20 & 9.8 \\
Perceived VMMC protection & 22 & 10.8 \\
Forgot & 28 & 13.7 \\
Type of sexual partner $(n=322)$ & $\mathrm{n}$ & $\%$ \\
Marital partner & 140 & 43.4 \\
Paid sex partner & 94 & 29.2 \\
Non cohabiting partner & 88 & 27.3 \\
Abstinence post VMMC $(n=322)$ & $\mathrm{n}$ & $\%$ \\
Less than six weeks & 104 & 32.3 \\
More than six weeks & 218 & 67.7 \\
STI ( $n=322)$ & $\mathrm{n}$ & $\%$ \\
Had STI & 38 & 11.8 \\
No STI & 284 & 88.2 \\
\hline
\end{tabular}

showed that VMMC participants living in high density areas were less likely to use condoms when having sex with non-cohabiting partners $(p$-value $=0.030)$. Furthermore, the study showed that those aged between 18 and 29 years, residing in low density locations, being unmarried / single, having secondary and tertiary education, being student and unemployed were significantly associated with being involved in transactional sex (Tablse 5-7).

\section{Univariate and multivariate analysis on sexual practices}

The odds of not using a condom during the last sexual encounter among those from high density residential areas was twice as higher compared to those from low density residential areas $(\mathrm{OR}=2.0,95 \% \mathrm{CI}=1.05-3.81)$. Age, marital status, occupation, religion and education were not statistically significant with non-condom use (Table 5).

On multiple sexual partners, the age group 25-29 was significantly associated with having multiple sex partners. The odds of having multiple sexual partners among those aged 25-29 was 2.22 times higher compared to those aged $18-24(\mathrm{OR}=2.22,95 \% \mathrm{CI}=1.18-4.20)$. The other age groups were not significant (Table 6).

On transactional sex, the odds of being involved in transactional sex among those aged 30-49 was 81.0\% less compared to those aged $18-29(\mathrm{OR}=0.19,95 \% \mathrm{CI}=$ 0.09-0.37). The odds of being involved in transaction sex among the married ones was $88.0 \%$ less compared to those that were single $(\mathrm{OR}=0.12,95 \% \mathrm{CI}=0.07-0.22)$. The odds of being involved in transaction sex among those that reside in high density areas was $55.0 \%$ less compared to those that reside in low density areas $(\mathrm{OR}=$ $0.45,95 \% \mathrm{CI}=0.27-0.74)$. On occupation; students and those that were unemployed were significantly associated with being involved in transaction sex. The odds of being involved in transaction sex was four times higher among the students compared to those with formal employment $(\mathrm{OR}=4.02,95 \% \mathrm{CI}=1.80-8.97)$ and the odds of being involved in transaction sex among those unemployed was six times higher compared to those with formal employment $(\mathrm{OR}=5.88, \quad 95 \% \mathrm{CI}=2.23-15.5)$ (Table 7).

\section{Multivariate analysis}

The final multivariate model included location, age, marital status, occupation and education. Of these, those residing in high density location were significantly associated with non-condom use $(\mathrm{aOR}=1.98,95 \% \mathrm{CI}=1.02-3.84)$ while being single $(\mathrm{aOR}=0.19,95 \% \mathrm{CI}=0.08-0.47)$, and residing in low density location $(\mathrm{aOR}=0.41,95 \% \mathrm{CI}=$ $0.22-0.76$ ) was significantly associated with being involved in transaction sex (Tables 5, 6 and 7). 
Table 5 Univariate and multivariate analysis on non-condom

\begin{tabular}{|c|c|c|c|c|c|c|c|}
\hline \multicolumn{8}{|c|}{ Univariate and multivariate logistic regression on non-condom use } \\
\hline Variable & & $\mathrm{OR}^{\neq}$ & $p$-value & $95 \% \mathrm{Cl}$ & $\mathrm{aOR}^{\dagger}$ & $p$-value & $95 \% \mathrm{Cl}$ \\
\hline \multirow[t]{2}{*}{ Age } & $18-29$ & 1 & & & & & \\
\hline & $30-49$ & 0.53 & 0.132 & $0.23-1.21$ & 0.48 & 0.244 & $0.14-1.65$ \\
\hline \multirow[t]{2}{*}{ Marital status } & Single & 1 & & & & & \\
\hline & Married & 0.71 & 0.357 & $0.35-1.46$ & 0.61 & 0.397 & $0.19-1.92$ \\
\hline \multirow[t]{3}{*}{ Education level } & Primary & 1 & & & & & \\
\hline & Secondary & 1.12 & 0.843 & $0.36-3.46$ & 1.59 & 0.473 & $0.44-5.59$ \\
\hline & Tertiary & 1.53 & 0.520 & $0.42-5.58$ & 3.41 & 0.112 & $0.75-15.50$ \\
\hline \multirow[t]{3}{*}{ Religion } & Christianity & 1 & & & & & \\
\hline & Islam & 1.39 & 0.563 & $0.46-4.18$ & 1.87 & 0.337 & $0.51-6.75$ \\
\hline & Others & 7.49 & 0.077 & $0.81-67.63$ & 6.81 & 0.100 & $0.69-66.87$ \\
\hline \multirow[t]{2}{*}{ Area of residence } & Low density & 1 & & & & & \\
\hline & High density & 2.00 & 0.034 & $1.05-3.81$ & 1.93 & 0.043 & $1.02-3.84$ \\
\hline \multirow[t]{5}{*}{ Occupation } & Formal employment & 1 & & & & & \\
\hline & Student & 1.81 & 0.279 & $0.62-5.34$ & 1.18 & 0.798 & $0.32-4.48$ \\
\hline & Farmer & 2.40 & 0.341 & $0.40-40.55$ & 1.76 & 0.599 & $0.21-14.30$ \\
\hline & Business & 3.20 & 0.064 & $0.92-10.98$ & 3.60 & 0.083 & $0.84-15.35$ \\
\hline & Unemployed & 1.60 & 0.484 & $0.43-5.95$ & 1.21 & 0.808 & $0.26-5.63$ \\
\hline
\end{tabular}

${ }^{\dagger}$ adjusted Odds Ratio, ${ }^{\ddagger}$ Odds Ratio

Table 6 Univariate and multivariate analysis on multiple sex partners

\begin{tabular}{|c|c|c|c|c|c|c|c|}
\hline \multicolumn{8}{|c|}{ Univariate and multivariate logistic regression on multiple sexual partners } \\
\hline Variable & & $\mathrm{OR}^{\ddagger}$ & $p$-value & $95 \% \mathrm{Cl}$ & $\mathrm{aOR}^{\dagger}$ & $p$-value & $95 \% \mathrm{Cl}$ \\
\hline \multirow[t]{5}{*}{ Age } & $18-24$ & 1 & & & & & \\
\hline & $25-29$ & 2.22 & 0.013 & $1.18-4.20$ & 2.28 & 0.037 & $1.05-4.95$ \\
\hline & $30-34$ & 1.11 & 0.79 & $0.41-2.46$ & 1.10 & 0.859 & $0.39-3.11$ \\
\hline & $35-49$ & 0.99 & 0.988 & $0.31-3.19$ & 0.95 & 0.942 & $0.23-3.85$ \\
\hline & $40-49$ & 1.91 & 1.570 & $0.78-4.67$ & 1.60 & 0.440 & $0.48-5.29$ \\
\hline \multirow[t]{2}{*}{ Marital status } & Single & 1 & & & & & \\
\hline & Married & 1.33 & 2.81 & $0.79-2.24$ & 1.04 & 0.922 & $0.44-2.49$ \\
\hline \multirow[t]{3}{*}{ Education level } & Primary & 1 & & & & & \\
\hline & Secondary & 1.62 & 0.247 & $0.72-3.66$ & 2.19 & 0.093 & $0.88-5.48$ \\
\hline & Tertiary & 1.83 & 0.247 & $0.66-5.11$ & 2.40 & 0.143 & $0.74-7.73$ \\
\hline \multirow[t]{3}{*}{ Religion } & Christianity & 1 & & & & & \\
\hline & Islam & 2.03 & 0.053 & $0.99-4.17$ & 2.10 & 0.066 & $0.95-4.64$ \\
\hline & Others & 0.54 & 0.420 & $0.12-2.44$ & 0.47 & 0.343 & $0.10-2.26$ \\
\hline \multirow[t]{2}{*}{ Area of residence } & Low density & 1 & & & & & \\
\hline & High density & 1.19 & 0.530 & $0.69-2.03$ & 1.06 & 0.855 & $0.57-1.10$ \\
\hline \multirow[t]{5}{*}{ Occupation } & Formal employment & 1 & & & & & \\
\hline & Student & 0.80 & 0.554 & $0.38-1.68$ & 0.92 & 0.883 & $0.34-2.50$ \\
\hline & Farmer & 0.88 & 0.817 & $0.30-2.60$ & 1.05 & 0.879 & $0.33-3.72$ \\
\hline & Business & 1.13 & 0.751 & $0.54-2.37$ & 1.11 & 0.820 & $0.46-2.66$ \\
\hline & Unemployed & 0.61 & 0.354 & $0.21-1.75$ & 0.61 & 0.416 & $0.43-2.49$ \\
\hline
\end{tabular}


Table 7 Univariate and multivariate analysis on transaction sex

\begin{tabular}{|c|c|c|c|c|c|c|c|}
\hline \multicolumn{8}{|c|}{ Univariate and multivariate logistic regression on transaction sex } \\
\hline Variable & & $\mathrm{OR}^{\ddagger}$ & $p$-value & $95 \% \mathrm{Cl}$ & $\mathrm{aOR}^{\dagger}$ & $p$-value & $95 \% \mathrm{Cl}$ \\
\hline \multirow[t]{2}{*}{ Age } & $18-29$ & 1 & & & & & \\
\hline & $30-49$ & 0.19 & $<0.001$ & $0.09-0.37$ & 0.46 & 0.118 & $0.17-1.22$ \\
\hline \multirow[t]{2}{*}{ Marital status } & Single & 1 & & & & & \\
\hline & Married & 0.12 & $<0.001$ & $0.07-0.22$ & 0.19 & $<0.001$ & $0.08-0.47$ \\
\hline \multirow[t]{3}{*}{ Education level } & Primary & 1 & & & & & \\
\hline & Secondary & 4.00. & 0.005 & $1.52-10.52$ & 2.30 & 0.136 & $0.77-6.91$ \\
\hline & Tertiary & 4.46 & 0.009 & $1.44-13.79$ & 2.67 & 0.148 & $0.71-10.02$ \\
\hline \multirow[t]{3}{*}{ Religion } & Christianity & 1 & & & & & \\
\hline & Islam & 0.70 & 0.368 & $0.32-1.53$ & 1.37 & 0.516 & $0.53-3.59$ \\
\hline & Others & 0.16 & 0.079 & $0.02-1.24$ & 0.18 & 0.127 & $0.02-1.63$ \\
\hline \multirow[t]{2}{*}{ Area of residence } & Low density & 1 & & & & & \\
\hline & High density & 0.45 & 0.002 & $0.27-0.74$ & 0.41 & 0.004 & $0.22-0.76$ \\
\hline \multirow[t]{5}{*}{ Occupation } & Formal employment & 1 & & & & & \\
\hline & Student & 4.02 & 0.001 & $1.80-8.97$ & 0.98 & 0.977 & $0.33-2.90$ \\
\hline & Farmer & 1.01 & 0.988 & $0.28-3.63$ & 2.04 & 0.342 & $0.47-8.90$ \\
\hline & Business & 1.11 & 0.819 & $0.45-2.73$ & 1.24 & 0.692 & $0.42-3.76$ \\
\hline & Unemployed & 5.88 & $<0.001$ & $2.23-15.53$ & 2.97 & 0.083 & $0.86-10.15$ \\
\hline
\end{tabular}

${ }^{\dagger}$ adjusted Odds Ratio, ${ }^{\ddagger}$ Odds Ratio

\section{Discussion}

Overall, the study found that more than one-third (38.2\%) of participants; that had undergone VMMC engaged in risky sexual practices. Only area of residence and marital status seem to play a significant role in the adoption of risky sexual practices among participants that had undergone VMMC in this study.

Residing in high density locations was significantly associated with non-condom use. High density locations of Mzuzu are mostly associated with low socioeconomic status hence access and affordability of condoms may be affected [29]. Low education levels may as well affect condom uptake and usage in those residing in high density locations [3]. This result is similar with findings that were observed in the Malawi Demographic and Health Studies (MDHS) where those residing in high density locations were less likely to use condoms [3]. In this regard, knowledge of the perceived protective effect of VMMC in such circumstances could overshadow the need to use other preventive measures like condom use, hence an increase in risky sexual practices.

Furthermore, being single / unmarried and residing in low density residential areas was significantly associated with being involved in transactional sex. Those residing in low density areas in Mzuzu are associated with wealth and higher education hence the likelihood of affording to pay for sex [3]. Most of the unmarried / singles in low density urban locations are mostly either students or employed and have a source of income. Access to information among those residing in low density location could have had an influenced the better understanding of the benefits that VMMC carries and this could have been the driving force to the risky sexual practice among the single / unmarried. This was also observed in a study done in Uganda where risky sexual behaviors were evident among the singles willing to be circumcised and residing in the urban region [30]. A study conducted in Sub-Saharan countries also demonstrated that the unmarried / singles, engage more in transactional sex compared to their married counterparts [31]. The study also observed that economic status has an influence on transactional sex and residing in low density areas of Mzuzu is associated with wealth and higher levels of education $[3,31]$.

While anecdotal observations show that there is a better perceived understanding that VMMC protects against contracting HIV, the results in this study show a variation in VMMC client's views. The study shows that a higher proportion of participants reported understanding that VMMC offers partial protection and that one can still acquire HIV if engages in unsafe sexual practices.

A study conducted done in South Africa showed that $75.5 \%$ of participants understood the partial protection offered by VMMC a percentage slightly lower as compared to this study [32] while another study conducted in Botswana, Namibia and Swaziland showed that 9.0$15.0 \%$ of the participants believe that circumcised men are fully protected against HIV compared to $12.7 \%$ from this current study [33]. Almost all of the participants 
reported the need to continue using condoms post VMMC and that one can still transmit the virus despite having undergone VMMC. Further to this, more than half of the participants reported being afraid of acquiring HIV if they subject themselves to risky sexual practices despite having undergone VMMC.

The participants' better understanding of VMMC messages as seen from this study could be attributed to an enhanced IEC strategy by the Ministry of Health $(\mathrm{MoH})$ through the use of mass media as a measure to combat rising pressure of possible risk compensation that is being imagined with the rolling out of VMMC in Malawi. This is further influenced by the availability of wide range of mass media and residing in an urban location [3] where access to information is high among the literate population who have undergone counselling prior to undergoing VMMC.

Nevertheless, $12.7 \%$ of the study participants had a perception that VMMC provides total protection against HIV acquisition and $2.5 \%$ of the study participants were not certain as to what VMMC offers in HIV prevention. These contrasting views could be attributed to message dissemination in relation to HIV and the protection that VMMC offers. VMMC being a new strategy in HIV prevention, most of the messages are focused on the HIV protection with little emphasis on the limitation of VMMC. Furthermore, to increase the uptake of VMMC in Malawi, campaigns are on the increase and message dissemination does not mostly emphasize on the limitation of VMMC [34]. In addition, participants' understanding and level of education could also have an impact on the uptake and interpretation of the messages that are packaged for VMMC awareness. In this regard, VMMC is being taken as a preventive measure against contracting HIV with little emphasis on its limitation putting at risk clients who may opt for VMMC and engage in risky sexual practices post VMMC owing to its protective effect.

Close to half (45.7\%) of the participants in this study agreed to have less fear of contracting HIV following VMMC, which may explain the discrepancy between knowledge and practice of participants that have undergone VMMC in this study where $38.2 \%$ still engaged in risky sexual practice despite knowing the level of protection that VMMC offers.

Contextually, VMMC seems to have opened an opportunity for participants that were previously afraid of engaging in risky sexual acts. A study by Kibira et al demonstrated that willingness to be circumcised was associated with risky sexual practice [30] putting forward an idea that being circumcised is likely to encourage clients to engage in risky sexual practices. Apart from the protection that VMMC offers in preventing HIV transmission, the perceived benefits of VMMC were also observed to be a driving factor for participants to go for VMMC [35].
This study found that $38.2 \%$ of the participants were involved in risky sexual practices post VMMC. Having multiple sexual partners constituted $23.7 \%$, being involved in transactional sex $29.2 \%$ and non-condom use at $36.9 \%(n=187)$. Studies by Kibira et al, Mapoma and Bwalya also demonstrated higher proportions of circumcised participants that were involved in risky sexual practices compared to their uncircumcised counterparts $[36,37]$. These findings show that there is an increase in risky sexual practices among circumcised participants. Furthermore, in a comparative study, risky sexual practices were less observed in the uncircumcised participants who showed interest to be circumcised than in the circumcised ones [38]. Similarly, a study done in Uganda observed that risky sexual behaviors were associated with willingness to be circumcised and this was evident among the youth, educated and residing in the urban region [30].

These finding supports the idea that undergoing VMMC is likely to encourage participants to engage in risky sexual acts. Results from a study done in Zimbabwe showed a strong association between willingness to be circumcised in participants that had risky sexual practices (multiple partners, being involved in transactional sex and non-condom use) [25]. This observation may explain the continued risky sexual practices in circumcised participants as being carried forward following circumcision and likely due to the perceived protective effect.

Nonetheless, the desire to have multiple sexual partners and engage in transactional sex influenced men to go for VMMC owing to the perceived protective effect of VMMC as observed from studies that were conducted in Zimbabwe and Botswana [30]. Further to this, a study done in Uganda showed that the HIV prevalence among the circumcised was low even with risky sexual practices [37]. These findings may negatively affect the promotion of safer sex practices among the circumcised and could be a driving factor for clients to opt for VMMC and consequently engage in risky sexual practices. Studies done in Zimbabwe, Zambia, two from Uganda and from the 14 prioritized VMMC countries showed that VMMC participants are engaging in risky sexual practices despite the proportions not being significant [37].

In addition, abstinence post VMMC also impacts on HIV transmission. In this study $32.3 \%$ (104) resumed sexual activity before 6 weeks and $63.5 \%$ were married. Engaging in sex with their marital partner among the married diffused their fear of contracting HIV. The risk of contracting HIV is higher in those that resume sexual activity in less than 6 weeks $[39,40]$.

Risky sexual practices are evident in the circumcised participants. Varied estimates have been observed from different studies on the risky sexual practices specifically on non-condom use, having multiple sexual partners 
and being involved in transactional sex. Proportions of those that self-reported engaging in risky sexual practices from this study (38.2\%), support the possibility of risky sexual practices arising from being circumcised. It has also been observed that the driving force for men to undergo VMMC was their risky sexual practice prior to getting circumcised. In addition, almost close to half of the participants self-reported less fear of contracting HIV post VMMC. The findings of this study have shown that VMMC participants are likely to engage in risky sexual practices owing to the perceived protective effect that VMMC offers.

Nevertheless, there are some limitations to this study. This study is cross-sectional and causal inferences cannot be drawn. It is also worth noting that the findings could also be limited by social desirability bias in participants' self-reporting of sexual risk practices during face to face interviews and also recall bias when reporting on their sexual practices.

\section{Conclusion}

HIV still poses a great threat to the livelihood worldwide with Sub-Saharan African bearing the highest burden of the pandemic. The study found that circumcised men are likely to engage in risky sexual practices owing to the perceived protective effect that VMMC offers. A higher proportion of men that underwent VMMC understand the protection that VMMC offers in preventing HIV transmission and the need to use condoms to avoid contracting the virus. Nevertheless, risky sexual practices were observed among circumcised men. There is need to strengthen the information, education and communication (IEC) component before, during and after circumcision with emphasis on the unmarried / single and those residing in low and high densities as they are at risk of engaging in risky sexual practices post VMMC. However, misunderstandings and inaccurate perceptions about protection from HIV through VMMC could lead clients to opt for risky sexual practices and reduce the ability for adopting options available for safer sex.

Further studies need to be done to ascertain if male circumcision has an impact on condom use and a study that incorporates pre and post circumcision sexual practices in participants.

\footnotetext{
Abbreviations

AIDS: Acquired Immune Deficiency Syndrome; ART: Antiretroviral therapy; CO: Commanding officer; COMREC: College of Medicine Research and Ethics Committee; DHO: District Health Office; HIV: Human Immunodeficiency Virus; IEC: Information, Education and Communication; JHPIEGO: John Hopkins Program for International Education in Gynecology and Obstetrics; MC: Male circumcision; MDHS: Malawi Demographic and Health Survey; MoH: Ministry of Health; PCl: Project Concern International; PI: Principal Investigator; RA: Research Assistant; STI: Sexually Transmitted Infections; UN: United Nations; UNAIDS: United Nations Programme on HIV and AIDS; VMMC: Voluntary Medical Male Circumcision; WHO: World Health Organization
}

\section{Acknowledgements}

All authors gratefully acknowledge the different roles played by the following: Dr. Jimmy Gama, Dr. Charles Masulani, Dr. Thokozani Bumbwe, Dr. Chingatichifwe Bwalwani Mbakaya, Emmanuel Mlelemba, Prince Majiga, John Eliya, Naomi Banda, Elizabeth Chatsika, Prisca Kaseko and Joseph Ntwana.

\section{Authors' contributions}

Study design, analysis and manuscript drafting was by ZJC. VJ assisted with study design and manuscript editing. VS, AK, SCA assisted with interpretation of findings, review and editing of the manuscript. All authors read and approved the final manuscript.

\section{Authors' information}

ZJC is a master's degree candidate at the Department of Public Health and $V J$ is a lecturer at College of Medicine, Department of Health Systems and Policy. VS, AK are lecturers at College of Medicine, Department of Public health and Research Support Centre respectively. SCA is an epidemiologist based at Malawi Military Health Service.

\section{Funding}

Not applicable

\section{Availability of data and materials}

The data of this study are available without restriction from the corresponding author.

\section{Ethics approval and consent to participate}

Ethical approval was obtained from the College of Medicine Research Ethics Committee in Malawi (issued January 6, 2017, reference number P.10/16/2035). Written permission to conduct the study in the health facilities namely Mzuzu and Moyale were obtained from the health facilities involved in the study. Participants were informed of their freedom not to participate in the study or to withdraw from the study at any point during the interview.

Completing the questionnaire was done in a private place to ensure privacy and to reduce external distractions as well as to maintain confidentiality by using unique identifiers instead of personal data. All participants gave their informed consent voluntarily through written signature or thumbprint. Study participants were informed about the purpose of study, risks and benefits as well as the right to withdraw from the study at any time and without adverse consequences.

\section{Consent for publication \\ Not applicable}

\section{Competing interests}

The authors declare that they have no competing interests.

\section{Author details}

${ }^{1}$ College of Medicine, Public Health Department, P/Bag 360, Chichiri, Blantyre 3, Malawi. ${ }^{2}$ Malawi Defence Force, Malawi Military Health Services, Moyale Barracks, P.O Box 23, Mzuzu, Malawi. ${ }^{3}$ College of Medicine, Research Support Centre, P/Bag 360, Chichiri, Blantyre 3, Malawi. ${ }^{4}$ Department of Epidemiology and Biostatistics, School of Public Health, University of Zambia, Post Box 50110, Lusaka, Zambia. ${ }^{5}$ Malawi Defence Force, Malawi Military Health Services, Kamuzu Barracks, Private Bag 43, Lilongwe, Malawi. ${ }^{6}$ College of Medicine, Department of Public health, Health Systems and Policy, P/Bag 360, Chichiri, Blantyre 3, Malawi.

Received: 16 July 2019 Accepted: 31 January 2020

Published online: 11 February 2020

References

1. amfAR. Statistics: Worldwide: 2015. http://www.amfar.org/worldwide-aidsstats/. Accessed 16 May 2016.

2. AVERT. HIV and AIDS in Malawi. 2016. http://www.avert.org/professionals/ hiv-around-world/sub-saharan-africa/malawi. Accessed 23 Aug 2016

3. National Statistical Office (NSO) [Malawi] and ICF. Malawi demographic and health survey 2015-16, vol. 2017. Zomba: NSO; 2017. https://dhsprogram. com/pubs/pdf/FR319/FR319.pdf. Accessed 18 May 2017

4. UNAIDS. Fact sheet 2015. http://www.unaids.org/en/resources/campaigns/ HowAIDSchangedeverything/factsheet. Accessed 16 May 2016. 
5. UNAIDS DATA 2018. http://www.unaids.org/en/resources/documents/2016/ how-many-people-living-with-HIV-access-treatment. Accessed 16 Apr 2019.

6. The Global HIV/AIDS epidemic. 2015. http://kff.org/global-health-policy/factsheet/the-global-hivaids-epidemic/. Accessed 16 May 2016.

7. Ruiz MS, Institute of Medicine (U.S.), Committee on HIV Prevention Strategies in the United States. No time to lose: getting more from HIV prevention. Washington, D.C.: National Academy Press; 2001. http://public. eblib.com/choice/publicfullrecord.aspx?p=3375244. Accessed 24 Jan 2019

8. Combination HIV Prevention: tailoring and coordinating biomedical, Behavioural and Structural Strategies to Reduce New HIV Infections http:// www.unaids.org/en/resources/documents/2010/20101006_JC2007_ Combination_Prevention_paper. Accessed 16 Jan 2019.

9. Auvert B, Taljaard D, Lagarde E, Sobngwi-Tambekou J, Sitta R, Puren A. Randomized, Controlled Intervention Trial of Male Circumcision for Reduction of HIV Infection Risk. PLOS Med. 2005;2(11):e298 https://journals. plos.org/plosmedicine/article?id=10.1371/journal.pmed.0020298.The ANRS 1265 Trial Accessed 17 Jan 2019.

10. Bailey RC, Moses S, Parker CB, Agot K, Maclean I, Krieger JN, et al. Male circumcision for HIV prevention in young men in Kisumu, Kenya: a randomised controlled trial. Lancet. 2007;369:14 https://www.ncbi.nlm.nih. gov/pubmed/17321310. Accessed 16 Jan 2019.

11. Weiss HA, Quigley MA, Hayes RJ. Male circumcision and risk of HIV infection in sub-Saharan Africa: a systematic review and meta-analysis. AIDS. 2000;14: 2361 https://journals.Iww.com/aidsonline/Fulltext/2000/10200/Male_ circumcision_and_risk_of_HIV_infection_in.18.aspx. Accessed 17 Jan 2019.

12. WHO and UNAIDS announce recommendations from expert meeting on male circumcision for HIV prevention. :3. https://www.who.int/mediacentre/ news/releases/2007/pr10/en/. Accessed 16 Jan 2019.

13. Morris BJ, Wamai RG, Henebeng EB, Tobian AA, Klausner JD, Banerjee J, et al. Estimation of country-specific and global prevalence of male circumcision. Popul Health Metrics. 2016;14:4 https:/pophealthmetrics.biomedcentral.com/ articles/10.1186/s12963-016-0073-5. Accessed 24 May 2016.

14. Drain PK, Halperin DT, Hughes JP, Klausner JD, Bailey RC. Male circumcision, religion, and infectious diseases: an ecologic analysis of 118 developing countries. BMC Infect Dis. 2006;6:172. https://doi.org/10.1186/1471-2334-6172 Accessed 24 May 2019.

15. Haacker M, Fraser-Hurt N, Gorgens M. Effectiveness of and financial returns to Voluntary Medical Male Circumcision for HIV prevention in South Africa: an incremental cost-effectiveness analysis. PLoS Med. 2016;13(5) Available from: http://www.ncbi.nlm.nih.gov/pmc/articles/PMC4854479/. Accessed 5 Dec 2016.

16. Mills $\mathrm{E}$ et al. Male circumcision for the prevention of heterosexually acquired HIV infection: a meta-analysis of randomized trials involving 11,050 men. PubMed - NCBI. https://www.ncbi.nlm.nih.gov/pubmed/18705758. Accessed 16 Jan 2019.

17. Lau FK, Jayakumar S, Sgaier SK. Understanding the socio-economic and sexual behavioural correlates of male circumcision across eleven voluntary medical male circumcision priority countries in southeastern Africa. BMC Public Health. 2015;15:813. https://doi.org/10.1186/s12889-015-2135-1 Accessed 15 May 2016.

18. 10 World's highest AIDS rates. About.com Education. http://geography. about.com/od/lists/a/aids.htm. Accessed 16 May 2016.

19. Ngalande RC, Levy J, Kapondo CPN, Bailey RC. Acceptability of male circumcision for prevention of HIV infection in Malawi. AIDS Behav. 2006; 10(4):377-85 https://www.researchgate.net/publication/6741720.

20. Stover J, Bollinger L, Izazola JA, Loures L, DeLay P, Ghys PD, et al. What Is Required to End the AIDS Epidemic as a Public Health Threat by 2030? The Cost and Impact of the Fast-Track Approach. PLOS ONE. 2016;1 1(5):e0154893 http://dx.plos.org/10.1371/journal.pone.0154893. Accessed 5 Jun 2017.

21. Kaufman MR, Smelyanskaya M, Van Lith LM, Mallalieu EC, Waxman A, Hatzhold K, et al. Adolescent sexual and reproductive health services and implications for the provision of Voluntary Medical Male Circumcision: Results of a systematic literature review. PLoS One. 2016;11(3):e0149892 http://www.ncbi.nlm.nih.gov/pmc/articles/PMC4777442/PLoSONE. Accessed 12 May 2016.

22. WHO, UNAIDS, JHPIEGO. Manual for male circumcision under local anaesthesia. who_mc_local_anaesthesia.pdf. http://www.int/hiv/pub/ malecircumcision/who_mc_local_anaesthesia.pdf. Accessed 15 May 2016.

23. May RW. Ethical considerations surrounding voluntary medical male circumcision (VMMC) in South Africa as an intervention for HIV prevention.
Thesis. Stellenbosch: Stellenbosch University; 2014. http://scholar.sun.ac.za/ handle/10019.1/86654. Accessed 24 Jun 2016

24. Herman-Roloff A, Bailey RC, Agot K. Factors associated with the early resumption of sexual activity following medical male circumcision in Nyanza Province, Kenya. AIDS Behav. 2012;16:1173-81 http://www.ncbi.nlm. nih.gov/pmc/articles/PMC3677080/. Accessed 25 May 2016.

25. Chikutsa A, Ncube AC, Mutsau S. Association between wanting circumcision and risky sexual behaviour in Zimbabwe: evidence from the 2010-11 Zimbabwe demographic and health survey. Reprod Health. 2015; http:// www.ncbi.nlm.nih.gov/pmc/articles/PMC4364469/.

26. Voluntary Medical Male Circumcision demand creation toolkit. 2015. https:// www.malecircumcision.org/resource/voluntary-medical-male-circumcisiondemand-creation-toolkit. Accessed 15 May 2016

27. Brooks RA, Etzel M, Klosinski LE, Leibowitz AA, Sawires S, Szekeres G, et al. Male circumcision and HIV prevention: looking to the future. AIDS Behav. 2010;14(5):1203-6 http://www.ncbi.nlm.nih.gov/pmc/articles/PMC2888947/. Accessed 25 May 2016.

28. Iliyasu Z, Abubakar IS, Sani IH, Jibo AM, Karaye IM, Salihu HM, et al. Male circumcision and HIV risk behavior among University students in Northern Nigeria. Am J Mens Health. 2013;7(2):94-101 http://jmh.sagepub.com/ content/7/2/94.short. Accessed 9 May 2016

29. Davidoff-Gore A, Luke N, Wawire S. Dimensions of poverty and inconsistent condom use among youth in urban Kenya. AIDS Care. 2011;23:1282-90 https://www.tandfonline.com/doi/full/10.1080/0954 0121.2011.555744. Accessed 5 Jan 2019.

30. Kibira SPS, Makumbi F, Daniel M, Atuyambe LM, Sandøy IF. Sexual risk behaviours and willingness to be circumcised among uncircumcised adult men in Uganda. PLOS ONE. 2015;10(12):e0144843 http://journals.plos.org/ plosone/article?id=10.1371/journal.pone.0144843. Accessed 15 May 2016.

31. Chatterji M, Murray N, London D, Anglewicz P. The factors influencing transactional sex among young men and women in 12 sub-Saharan African countries. Soc Biol. 2005;52(1-2):56-72. https://doi.org/10.1080/19485565. 2002.9989099 Accessed 24 Jan 2019.

32. Hoffman JR, Arendse KD, Larbi C, Johnson N, Vivian LMH. Perceptions and knowledge of voluntary medical male circumcision for HIV prevention in traditionally non-circumcising communities in South Africa. Glob Public Health. 2015;10(5-6):692-707 http://www.ncbi.nlm.nih.gov/pubmed/2572 7250 Accessed 19 Apr 2016.

33. Andersson N, Cockcroft A. Male circumcision, attitudes to HIV prevention and HIV status: a cross-sectional study in Botswana, Namibia and Swaziland. AIDS Care. 2012;24:301 http://www.ncbi.nlm.nih.gov/pmc/articles/PMC33 79742/. Accessed 17 May 2016.

34. Muzyka CN, Thompson LH, Bombak AE, Driedger SM, Lorway R. A Kenyan newspaper analysis of the limitations of voluntary medical male circumcision and the importance of sustained condom use. BMC Public Health. 2012;12:465 https://bmcpublichealth.biomedcentral.com/articles/1 0.1186/1471-2458-12-465. Accessed 19 Jan 2019.

35. Muhamadi L, Ibrahim M, Wabwire-Mangen F, Peterson S, Reynolds SJ. Perceived medical benefit, peer/partner influence and safety and cost to access the service: client motivators for voluntary seeking of medical male circumcision in lganga district eastern Uganda, a qualitative study. Pan Afr Med J. 2013;15:117 https:// www.ncbinlm.nih.gov/pubmed/24255723. Accessed 4 Apr 2016.

36. Mapoma CC, Bwalya BB. Does circumcision influence risky sexual behaviour among circumcised sexually active men in Zambia? Evidence from the 2013-14 Zambia Demographic and Health Survey. Sex Transm Infect. 3(4):5. http://znphi.co.zm/thehealthpress/does-circumcision-influence-risky-sexualbehaviour-among-circumcised-sexually-active-men-in-zambia-evidencefrom-the-2013-14-zambia-demographic-and-health-survey/ http://znphi.co. zm/thehealthpress/wp-content/uploads/2017/03/THPZ_V1__2.pdf\#page=13. Accessed 20 Jun 2017.

37. Kibira SP, Nansubuga E, Tumwesigye NM, Makumbi F, Atuyambe L, Nviiri HN. Male Circumcision and Risky Sexual Behavior in a High HIV prevalence Country: Evidence from a National Survey in Uganda https://www. researchgate.net/profile/Simon_Kibira/publication/267637226_Male_ Circumcision_and_Risky_Sexual_Behavior_in_a_High_HIV_prevalence Country Evidence_from_a_National_Survey_in_Uganda/links/545632efocf2 cf5164802cdd.pdf. Accessed 30 May 2016.

38. Ayiga N, Letamo G. Impact of male circumcision on HIV risk compensation through the impediment of condom use in Botswana. Afr Health Sci. 2011; 11:550-9 http://www.ncbi.nlm.nih.gov/pmc/articles/PMC3362967/. Accessed 15 May 2016. 
39. Ediau M, Matovu JK, Byaruhanga R, Tumwesigye NM, Wanyenze RK. Risk factors for HIV infection among circumcised men in Uganda: a case-control study. J Int AIDS Soc. 2015;18. https://doi.org/10.7448/ias.18.1.19312 http:// jiasociety.org/jias/index.php/jias/article/view/19312. Accessed 18 May 2017.

40. Toefy Y, Skinner D, Thomsen SC. "What do You Mean I've Got to Wait for Six Weeks?!" Understanding the Sexual Behaviour of Men and Their Female Partners after Voluntary Medical Male Circumcision in the Western Cape. PloS One. 2015;10(7):e0133156 https://www.ncbi.nlm.nih.gov/pubmed/261 76946. Accessed 19 Apr 2016.

\section{Publisher's Note}

Springer Nature remains neutral with regard to jurisdictional claims in published maps and institutional affiliations.

Ready to submit your research? Choose BMC and benefit from:

- fast, convenient online submission

- thorough peer review by experienced researchers in your field

- rapid publication on acceptance

- support for research data, including large and complex data types

- gold Open Access which fosters wider collaboration and increased citations

- maximum visibility for your research: over $100 \mathrm{M}$ website views per year

At $\mathrm{BMC}$, research is always in progress.

Learn more biomedcentral.com/submissions 